\title{
Editorial
}

\section{Enfermagem na Conferência Internacional do Trabalho}

A Conferência da OIT terá discutido, em Genebra, em sua 61. ${ }^{a}$ Reunião, de junho de 1976, emprego e condições de trabalho e de vida do per soal de enfermagem. Como preparo para a Reunião, foi publicado o Informe n..$^{\circ}$ II (2), com o título sobre essa matéria referida.

Deveria a Conferência adotar um instrumento internacional sobre a condição do pessoal de enfermagem? Sim, foi a resposta de 44 dentre 53 países que haviam respondido a consulta.

Vejamos quais as profissões e categorias ocupacionais que a OIT enquadra como pessoal de enfermagem. Para nós, podemos dizer que são as mesmas que o Conselho Federal de Enfermagem abrange, a saber: 1) en. fermeiros, inclusive obstetrizes, 2) técnicos e auxiliares de enfermagem, que o documento descreve como "a pessoa que deve haver seguido um programa de ensino geral ou técnico do sistema de ensino secundário no qual se proporcionam as bases para o exercício da profissão nos aspectos da assistência geral ao paciente, de maneira menos complexa, e que requer conhecimentos técnicos e psicológicos, e que qualifica o educando para que posso c.bter um diplama expedido pela autoridade competente do país. As pessass desta categoria deverão poder prestar assistência preventiva, curativa ou de reabilitação em estabelecimentos institucionais ou municipais, nos quais se levem em consideração as necessidades psicológicas e sociais dos diferentes pacientes. Designam-se essas pessoas nos diferentes paises como "enfermeira ou enfermeiro prático", "enfermeira ou enfermeiro prático diplomado", assistant nurse, infirmière brevetée, etc." $A$ seguuir, a descrição das três categorias abrangidas refere-se à terceira, que é o atendente.

Deverá haver, depois de realizada a Reunião, um relatório ao nosso Conselho Federal de Enfermagem, a ser apresentado pelas duas Observadoras que o Governo brasileiro enviou à Conferência.

Os assuntcs resolvidos são de grande importância para as condiçōes, no mundo, do crescimento e desenvolvimento das profissões e ocupações de enfermagem.

( $H G D)$ 